ISSN. 2775-4324 (Online)

Journal of Physical Activity and Sports

Volume 2, Nomor 2, Agustus 2021, 248-254

Journal of Physical Activity and Sports

\title{
TINJAUAN SARANA DAN PRASARANA PEMBELAJARAN PENDIDIKAN JASMANI PADA SD NEGERI DI KELURAHAN BATURSARI KECAMATAN MRANGGEN KABUPATEN DEMAK
}

\author{
Beni Apriawan, Husnul Hadi, Asep Ardiyanto \\ Universitas PGRI Semarang, Jalan Sidodadi Timur No. 24 Dr. Cipto, Semarang, Indonesia \\ * Coressponding Author. Email: bennyaprawan98@gmail.com, husnulhadi@upgris.ac.id, \\ ardiyanto.hernanda@gmail.com
}

Received: 20 Desember 2020; Revised: 24 Agustus 2021; Accepted: 31 Agustus 2021

\begin{abstract}
Physical education facilities and infrastructure is one of the elements supporting the success of physical education learning. The need for physical education learning facilities and infrastructure is very vital, meaning that physical education must use facilities and infrastructure according to needs. In fact, it was found that physical education learning facilities and infrastructure were adequate and tended to be lacking. Physical education facilities are media or teaching aids in physical education. The infrastructure itself is divided into two, namely infrastructure or tools and infrastructure or facilities. Ideally, this tool should not be moved so that it is not easily damaged unless the space is limited so it must always be disassembled. Then infrastructure or facilities are everything that is needed in physical education learning, is permanent or cannot be moved.

The research used in this research is survey research. This research does not test hypotheses or does not use hypotheses, but only describes what information is in accordance with the variables studied. The subjects in this study were SD Negeri 1-7 in Batursari Village, Mranggen District, Demak Regency.

The results of the calculation explain that the total number, condition and ownership of facilities and infrastructure is SD N 1 Batursari is a school that totals all of the number, condition and ownership of facilities and infrastructure in the high category compared to other schools. Schools in the medium category are SD N 2 Batursari, SD N 5 Batursari, SD N 6 Batursari and SD N 7 Batursari. Schools in the low category are SD N 3 Batursari and SD N 4 Batursari.

Based on the results of research and data on physical education facilities and infrastructure in State Elementary Schools in Batursari Village, Mranggen District, Demak Regency, only a small part of the physical education facilities and infrastructure owned by each school, most of the facilities and infrastructure are still in good condition and ownership status of all facilities and infrastructure are their own.
\end{abstract}

Keywords: Facilities, Infrastructure, Physical Education.

\begin{abstract}
Abstrak
Sarana dan prasarana pendidikan jasmani merupakan salah satu unsur penunjang keberhasilan pembelajaran pendidikan jasmani. Kebutuhan sarana dan prasarana pembelajaran pendidikan jasman adalah sangat vital artinya bahwa pendidikan jasmani harus meggunakan sarana dan prasarana sesuai dengan kebutuhan. Pada kenyataannya ditemukan bahwa sarana dan prasarana pembelajaran penjasorkes cukup memadahi dan cenderung kurang. Sarana pendidikan jasmani merupakan media atau alat peraga dalam pendidikan jasmani. Prasarana itu sendiri dibagi menjadi dua yaitu prasarana atau perkakas dan prasarana atau fasilitas. Perkakas ini idealnya tidak dipindahpindahkan agar tidak mudah rusak kecuali kalau memang tempatnya terbatas sehingga harus selalu bongkar pasang. Kemudian prasarana atau fasilitas adalah segala sesuatu yang diperlukan dalam pembelajaran pendidikan jasmani, bersifat permanen atau tidak dapat dipindah-pindahkan. Penelitian yang digunakan dalam penelitian ini adalah penelitian survai Penelitian ini tidak menguji hipotesis atau tidak menggunakan hipotesa, melainkan hanya mendeskripsikan informasi apa adanya sesuai dengan variabel-variabel yang diteliti. Subjek dalam penelitian ini adalah SD Negeri 1-7 di Kelurahan Batursari Kecamatan Mranggen Kabupaten Demak.Hasil perhitungan menjelaskan bahawa bahwa total jumlah, kondisi dan kepemilikan sarana dan prasarana adalah SD N 1 Batursari merupakan sekolah yang total semua dari jumlah, kondisi dan kepemilikan sarana dan prasarana dalam katagori tinggi dibanding dengan sekolah lain. Sekolah dalam katagori sedang yaitu SD N 2 Batursari, SD N 5 Batursari,
\end{abstract}


Tinjauan Sarana Dan Prasarana Pembelajaran Pendidikan Jasmani Pada Sd Negeri Di Kelurahan Batursari Kecamatan Mranggen Kabupaten Demak, Beni Apriawan

SD N 6 Batursari dan SD N 7 Batursari. Sekolah dalam kategori rendah yaitu SD N 3 Batursari dan SD N 4 Batursari.

Berdasarkan hasil penelitian dan data-data tentang sarana dan prasarana pendidikan jasmani di Sekolah Dasar Negeri di Kelurahan Batursari Kecamatan Mranggen Kabupaten Demak hanya sebagian kecil sarana dan prasarana pendidikan jasmani yang dimiliki tiap sekolah, sarana dan prasarana sebagian besar masih dalam kondisi baik dan status kepemilikan semua sarana dan prasarana merupakan milik sendiri.

Kata kunci : Sarana, Prasarana, Pendidikan Jasmani

\section{PENDAHULUAN}

SD merupakan salah satu pendidikan dimana didalamnya terdapat mata pelajaran pendidikan jasmani olahraga, dan kesehatan. Berdasarkan salah satu tujuan diatas yaitu keterampilan gerak, maka didalam pembelajaran dibutuhkan sarana dan prasarana pendidikan jasmani yang memadai agar suatu program pengajaran berjalan dengan baik. Untuk menunjang proses pembelajaran pendidikan jasmani dan mencapai keberhasilan saat ditentukan oleh beberapa faktor antara lain : manajemen sekolah, guru, siswa, sarana dan prasarana dan lingkungan yang mendukung.

Sarana dan prasarana pendidikan jasmani merupakan salah satu unsur penunjang keberhasilan pembelajaran pendidikan jasmani. Kebutuhan sarana dan prasarana pembelajaran pendidikan jasman adalah sangat vital artinya bahwa pendidikan jasmani harus meggunakan sarana dan prasarana sesuai dengan kebutuhan. Menurut Slameto (2010:64) faktor yang mempengaruhi pembelajaran mencangkup metode mengajar, kurikulum, relasi guru dengan siswa, relasi siswa dengan siswa, disiplin sekolah, alat/sarana pelajaran dan waktu sekolah. Guru merupakan unsur yang paling menentukan keberhasilan proses pembelajaran Penjas.

Pada observasi singkat pada 12 Agustus 2020 yang peneliti lakukan pada salah satu sekolah dan melakukan wawancara singkat pada salah satu guru penjarorkes (MF) pada SD yang ada di Batursari Kelurahan Batursari Kecamatan Mranggen Kabupaten Demak memperoleh hasil sebagai berikut:

"rata-rata siswa perkelas ada 30 anak, untuk sarpras cukup tapi cenderung kurang, karena sarpras dari biaya swadaya sekolah. Cukup tapi memang harus bergantian tiap anak. Untuk kondisi cukup baik namun harus ada pergantian."

Dari jawaban guru penjasorkes diatas dapat disimpulkan bahwa sarana dan prasarana yang menunjang pembelajaran penjasorkes cukup memadahi dan cenderung kurang, beliau juga menyampaikan bahwa sarana dan prasarana yang menunjang pembelajaran merupakan hasil swadaya sekolah. Bahagia \& Mujianto (dalam Lubay \& Purnama, 2019) menjelaskan 
bahwa keberadaan perlengkapan penjas sangat diperlukan, namun di sisi lain peralatan dan perlengkapan penjas yang dimiliki sekolah-sekolah biasanya kurang memadai, baik dalam segi kualitas maupun kuantitas. Tidak sedikit kegiatan pendidikan jasmani yang tidak dapat terlaksana dengan baik karena hambatan fasilitas yang tidak memadai.

Sarana dan prasarana merupakan salah satu faktor penunjang untuk mencapai hasil belajar yang optimal. Dalam pengajaran pendidikan jasmani olahraga dan kesehatan sarana dan prasarana yang memadai sangat penting untuk meningkatkan dan mengembangkan kualitas proses belajar mengajar pendidikan jasmani. Jumlah, kondisi dan kepemilikan sarana dan prasarana pendidikan jasmani olahraga dan kesehatan besar sekali manfaatnya bagi guru dan siswa, sehingga pembelajaran dapat berjalan lancar serta tujuan pembelajaran dapat tercapai dengan baik. Namun sebaliknya sarana dan prasarana yeng tidak lengkap atau tidak sesua dengan kurikulum akan menyulitkan Guru dan siswa sehingga materi tidak dapat disampaikan pada siswa dan tujuan pembelajaran tidak dapat tercapai.

Kurangnya sarana pendidikan jasmani akan menghambat memanipulasi gerak pada siswa. Siswa akan mengantri dalam pergantian menggunakan peralatan pendidikan jasmani, siswa akan menjadi bosan dan siswa banyak beristirahat. Ini akan mengakibatkan kebugaran tidak akan tercapai. Hal tersebut harus dihindari demi kebugaran siswa, maka sarana pendidikan jasmani harus disesuaikan dengan jumlah siswa dan mengkondisikannya dengan baik agar pembelajaran pendidikan jasmani dapat berjalan dengan lancar dan mendukung

Prasarana pendidikan jasmani tidaklah harus berupa lapangan yang luas atau tidak harus lintasan lari yang sebenarnya. Prasarana pendidikan jasmani dapat dimodifikasi meski itu di luar arena, misalnya jalan, pohon dan lain sebagainya, yang terpenting adalah siswa dapat bergerak agar tercapainya kebugaran. Untuk dapat melaksanakan pembelajaran dengan baik maka dapat melakukan pembelajaran dengan pendekatan modifikasi. Ini dikarenakan agar siswa tidak mudah bosan dan jenuh saat melaksanakan proses pembelajaran pendidikan jasmani.Terdapatnya jumlah, kondisi dan kepemilikan sarana dan prasarana dengan kondisi dan keadaan yang baik di sekolah dapat menarik keantusiasan siswa untuk melakukan kegiatan olahraga dalam mata pelajaran pendidikan jasmani.

Bukan sebaliknya, jangan sampai siswa menjadi takut untuk melakukan aktivitas olahraga karena sarana dan prasarana yang tidak memenuhi syarat, misalnya sarana dan prasarana yang rusak, sarana dan prasarana yang membahayakan, sarana dan prasarana yang membosankan dan lain sebagainya. Sehingga guru pendidikan jasmani harus dapat mengatasi bagaimana caranya untuk memenuhi persyaratan sarana dan prasarana pendidikan jasmani 
Tinjauan Sarana Dan Prasarana Pembelajaran Pendidikan Jasmani Pada Sd Negeri Di Kelurahan Batursari Kecamatan Mranggen Kabupaten Demak, Beni Apriawan

sebaik mungkin.

Walapun peneliti sudah melakukan observasi singkat dan wawancara singkat, peneliti masih belum bisa mengetahui bagaimana jumlah, kondisi dan kepemilikan sarana prasarana pendidikan jasmani pada SD Negeri di Kelurahan Batursari Kecamatan Mranggen Kabupaten Demak. Dengan kata lain sarana dan prasarana pendidikan jasmani pada SD Negeri di Kelurahan Batursari Kecamatan Mranggen Kabupaten Demak ini masih belum diketahui. Selain kondisi sarana dan prasarana pendidikan jasmani, peneliti juga belum mengetahui jumlah, kondisi dan kepemilikan sarana dan prasarana pendidikan jasmani yang ada. Dan jika sarana dan prasarana pendidikan jasmani itu lengkap adanya, apakah sarana dan prasarana pendidikan jasmani dalam kondisi baik dan di laksanakan atau dipakai sebagai media pembelajaran pendidikan jasmani secara optimal, itu juga masih membuat kejanggalan peneliti. Ini membuat peneliti terdorong untuk meneliti kondisi sarana dan prasarana pendidikan jasmani pada SD di Kelurahan Batursari Kecamatan Mranggen Kabupaten Demak.

\section{Metode}

Penelitian ini merupakan penelitian penelitian survai. Menurut Arikunto (2010:156), survei adalah suatu aktivitas memperhatikan suatu objek dengan menggunakan mata. Hasil dalam penelitian kemudian dijelaskan secara deskriptif. Penelitian ini bertujuan untuk mengetahui jumlah, kondisi dan kepemilikan sarana dan prasarana pendidikan jasmani SD Negeri 1-7 di Kelurahan Batursari Kecamatan Mranggen Kabupaten Demak.

\section{Hasil dan Pembahasan}

Penelitian ini dilakukan di 7 Sekolah Dasar yang ada di Kelurahan Batursari Kecamatan Mranggen Kabupaten Demak. Adapun sekolahnya yaitu SD N 1 Batursari - SD N 7 Batursari. Perlaksanaan penelitian sebanyak 1 kali pertemuan pada masing-masing subjek sesuai dengan kesepakatan dengan guru penjasorkes tiap sekolah.

Penelitian ini dilakukan untuk mengetahui jumlah, kondisi dan status kepemilikan sarana dan prasarana pendidikan jasmani di Sekolah Dasar Negeri di Kelurahan Batursari Kecamatan Mranggen Kabupaten Demak. Penelitian dilakukan dari tanggal 11 November 2020 - 14 November 2020. Pada penelitian ini pengambilan data menggunakan checklist, pengisian sesuai dengan keadaan yang ada berdasarkan apa yang penulis lihat dan penulis dengar dari penjelasan guru penjasorkes tiap sekolah.

Berdasarkan hasil olah data yang telah diuraikan dari penelitian survei sarana dan prasarana pendidikan jasmani Sekolah Dasar Negeri di Kelurahan Batursari Kecamatan 
Mranggen Kabupaten Demak yang meliputi pokok bahasan sesuai dengan BNSP (2006) yaitu: permainan olahraga, atletik, aktivitas senam, beladiri, aktivitas aquatik dan pendidikan luar kelas. Hasil yang diperoleh dari tiap sekolah beragam namun secara garis besar semua sekolah masih butuh adanya penambahan sarana dan prasarana pendidikan penjasorkes untuk menunjang pembelajaran penjasorkes.

Dari hasil penelitian pada pokok bahasan permainan olahraga, sarana yang dimiliki oleh semua sekolah adalah bola sepak dan bola sepak takraw. Ada sarana yang sama sekali tidak dimiliki oleh semua sekolah, sarana tersebut adalah jaring gawang. Jumlah sarana paling banyak yaitu bola rounders, walaupun jumlah sarana tersebut paling banyak namun hanya SD N 1 Batursari, SDN 2 Batursari dan SD N 5 Batursari yang memiliki sarana tersebut. Sedangkan untuk sarana yang jumlahnya paling sedikit adalah shuttlecock hanya dimiliki oleh SD N 7 Batursari.

Pokok bahasan kedua adalah atletik, pada sarana atletik ada sekolah yang sama sekali tidak memiliki sarana untuk atletik adapun sekolah tersebut adalah SDN 1 Batursari, SDN 3 Batursari dan SDN 4 Batursari. Pada sarana atletik SD N 2 Batursari dan SD N 5 Batursari hanya memiliki meteran, sedangkan SD N 5 Batursari hanya memiliki tongkat estafet. Sekolah yang paling banyak memiliki sarana atletik adalah SD N 7 Batursari, sekolah tersebut memiliki galah lompat tinggi, meteran, tongkat estafet dan start block.

Dari pokok bahasan ketiga yaitu senam, hanya ada dua jenis sarana yang hanya dimiliki satu sekolah yaitu SD N 2 Batursari memiliki kaset SKJ dan tape recorder. Pokok bahasan keempat yaitu beladiri, semua sekolah tidak memiliki sarana beladiri yaitu baju beladiri. Pokok bahasan kelima yaitu aktivitas akuatik, hanya ada satu jenis sarana yang dimiliki satu sekolah yaitu SD N 6 Batursari memiliki pelampung renang. Pokok bahasan teraktir atau keenam yaitu pendidikan diluar sekolah, hanya ada satu jenis sarana yang dimiliki dua sekolah yaitu SD N 1 Batursari dan SD N 3 Batursari memiliki tenda.

Hasil perhitungan di atas menjelaskan bahwa total jumlah, kondisi dan kepemilikan sarana dan prasarana adalah SD N 1 Batursari merupakan sekolah yang total semua dari jumlah, kondisi dan kepemilikan sarana dan prasarana dalam katagori tinggi dibanding dengan sekolah lain. Sekolah dalam katagori sedang yaitu SD N 2 Batursari, SD N 5 Batursari, SD N 6 Batursari dan SD N 7 Batursari. Sekolah dalam kategori rendah yaitu SD N 3 Batursari dan SD N 4 Batursari.

Dari 7 Sekolah Dasar Negeri di Kelurahan Batursari Kecamatan Mranggen Kabupaten Demak untuk sarana pendidikan jasmani tidak semuanya dimiliki, masih banyak sarana 
Tinjauan Sarana Dan Prasarana Pembelajaran Pendidikan Jasmani Pada Sd Negeri Di Kelurahan Batursari Kecamatan Mranggen Kabupaten Demak, Beni Apriawan

pendidikan jasmani yang tidak dimiliki bahkan semua sekolah tidak memiliki seperti jaring gawang, bendera kecil, nomor dada, gadai, sampai, balok senam, tongkat senam, kaset SSB, kepet renang, tali plastic dan tongkat. Sebagian besar sarana yang dimiliki mengikuti apa yang menjadi kesenangan siswa seperti bola sepak, bola voli, bola basket dan kun yang merupakan temuan baru. Kondisi sarana yang ditunjukan oleh hasil penelitian hanya ada beberapa sarana pendidikan jasmani yaitu bola sepak, bola voli dan bola basket kondisinya yang rusak, namun semua kepemilikan sarana pendidikan jasmani berstatus milik sendiri.

Jumlah jenis prasarana (perkakas) pendidikan jasmani juga tidak semua dimiliki oleh Sekolah Dasar Negeri di Kelurahan Batursari Kecamatan Mranggen Kabupaten Demak jenis prasarana (perkakas) yang sama sekali tidak dimiliki semua sekolah adalah gawang sepak bola, papan skor, mistar lompat tinggi, balok keseimbangan, bangku swedia, peti lompat dan samsak berdiri. Kondisi prasarana (perkakas) yang ditemukan dari data penelitian adalah sebagian besar dalam kondisi baik dan hanya ada 1 jenis prasarana (perkakas) yang rusak yaitu matras. Status kepemilikan untuk jenis prasarana (perkakas) pendidikan adalah milik sendiri tidak ada status kepemilikan yang menyewa dan meminjam.

Sedangkan untuk jumlah prasarana (fasilitas) pendidikan yang dimiliki Sekolah Dasar Negeri di Kelurahan Batursari gudang olahraga, halaman sekolah dan lapangan olahraga. Semua prasarana (fasilitas) pendidikan jasmani dalam kondisi baik dan untuk status kepemilikan prasarana (fasilitas) pendidikan jasmani adalah milik sendiri tanpa ada prasarana (fasilitas) pendidikan jasmani yang menyewa dan meminjam.

Berdasarkan hasil penelitian tentang sarana dan prasarana pendidikan jasmani di Sekolah Dasar Negeri di Kelurahan Batursari Kecamatan Mranggen Kabupaten Demak hanya sebagian kecil sarana dan prasarana pendidikan jasmani dimiliki tiap sekolah. Hal tersebut dikarenakan sekolah lebih memprioritaskan sarana dan prasarana pendidikan jasmani yang lebih sering dipergunakan dan disukai oleh kebanyakan siswa pada umumnya, seperti bola sepak, bola voli bola basket, bola sepaktakraw, pemukul tonnis dan kun.

\section{Penutup}

Berdasarkan hasil penelitian dan data-data tentang sarana dan prasarana pendidikan jasmani di Sekolah Dasar Negeri di Kelurahan Batursari Kecamatan Mranggen Kabupaten Demak, hanya sebagian kecil sarana dan prasarana pendidikan jasmani yang dimiliki tiap sekolah, sarana dan prasarana sebagian besar masih dalam kondisi baik dan status kepemilikan semua sarana dan prasarana merupakan milik sendiri.

Bagi pihak sekolah dan pihak atau intansi terkait dengan diketahuinya jumlah 
keberadaan, kondisi dan status kepemilikan sarana dan prasarana pendidikan jasmani dapat menentukan langkah berikutnya agar masalah jumlah, kondisi dan kepemilikan sarana dan prasaran pendidikan jasmani yang sesuai pembelajaran pendidikan jasmani di sekolah dapat segera terlaksana agar kegiatan pembelajaran pendidikan jasmani dapat terlaksana dengan baik dan berjalan sesuai yang diharapkan.

Bagi peneliti yang ingin melakukan penelitian sejenis, penelitian ini dapat digunakan sebagai wacana dan tolak ukur untuk dapat dikembangkan dalam instrumen penelitian dan populasi yang lebih luas.

Bagi peneliti, dengan adanya penelitian ini semoga dapat bermanfaat untuk pihak-pihak yang terkait seperti untuk sekolah dan guru penjasorkes. Dengan adanya penelitian ini masalah yang ada karena kurangnya sarana dan prasarana segera terpenuhi mengingat penelitian ini juga diharapkan memiliki manfaat praktis dan bisa memberikan masukan atau saran untuk sekolah maupun instansi yang terkait

\section{Daftar Pustaka}

Arikunto, S. (2010). Prosedur Penelitian (Suatu Pendekatan Praktik). Jakarta: Rineka Cipta. BNSP.(2006). Ruang Lingkup Penjasorkes. Jakarta: Depdiknas.

Lubay, L. H., \& Purnama, A. D. (2019). An Effort to Improve the Playing Skill Through the Application of Tool Modification in Small Ball Game (A Classroom Action Research). Advances in Health Sciences Research, volume 21 4th International Conference on Sport Science, Health, and Physical Education (ICSSHPE 2019)

Slameto. (2010). Belajar dan Faktor-faktor yang Mempengaruhinya. Jakarta : Rineka Cipta 